\title{
Contributions of the Atmospheric Radiation Measurement (ARM) Program and the ARM Climate Research Facility to the U.S. Climate Change Science Program
}
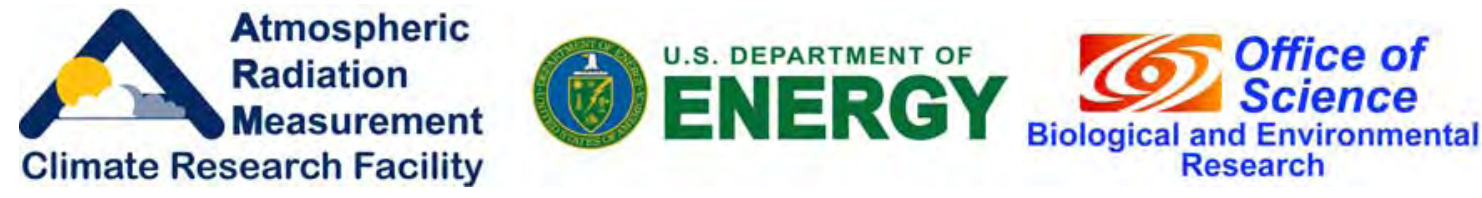

Work supported by the U.S. Department of Energy,

Office of Science, Office of Biological and Environmental Research 


\section{DISCLAIMER}

This report was prepared as an account of work sponsored b y the U.S. Government. Neither the United States nor an agency thereof, nor any of their employees, makes any warranty, express or implied, or assumes any legal liability or responsibility fo $r$ the accuracy, co mpleteness, o $r$ usefulness of any information, apparatus, product, or process di sclosed, or represents that its use would not infringe privately owned rights. Reference herein to any specific co mmercial product, process, or service by trade name, trademark, manuf acturer, or oth erwise, does not necessarily constitute or imply its endorsem ent, reco mmendation, or favoring by the U.S. Government or any agency thereof. The views and opinions of authors expres sed herein do not necess arily state or reflect those of the U.S. Government or any agency thereof. 


\section{Executive Summary}

The Earth's surface temperature is determined by the balance between incoming solar radiation and thermal (or infrared) radiation emitted by the Earth back to space. Changes in atmospheric composition, including greenhouse gases, clouds, and aerosols can alter this balance and produce significant climate change. Global climate models (GCMs) are the primary tool for quantifying future climate change; however, there remain significant uncertainties in the GCM treatment of clouds, aerosol, and their effects on the Earth's energy balance.

The 2007 assessment (AR4) by the Intergovernmental Panel on Climate Change (IPCC) reports a substantial range among GCMs in climate sensitivity to greenhouse gas emissions. The largest contributor to this range lies in how different models handle changes in the way clouds absorb or reflect radiative energy in a changing climate (Solomon et al. 2007).

In 1989, the U.S. Department of Energy (DOE) Office of Science created the Atmospheric Radiation Measurement (ARM) Program within the Office of Biological and Environmental Research (BER) to address scientific uncertainties related to global climate change, with a specific focus on the crucial role of clouds and their influence on the transfer of radiation in the atmosphere. To address this problem, BER has adopted a unique two-pronged approach:

- The ARM Climate Research Facility (ACRF), a scientific user facility for obtaining long-term measurements of radiative fluxes, cloud and aerosol properties, and related atmospheric characteristics in diverse climate regimes.

- The ARM Science Program, focused on the analysis of ACRF data to address climate science issues associated with clouds, aerosols, and radiation, and to improve GCMs.

This report describes accomplishments of the BER ARM Program toward addressing the primary uncertainties related to climate change prediction as identified by the IPCC. A selection of key accomplishments is summarized below.

Establishing a new standard for climate research observations. ARM was the first climate research program to deploy a suite of cutting-edge instrumentation for obtaining continuous measurements of cloud and aerosol properties (Ackerman and Stokes 2003). This strategy revolutionized our ability to collect long-term statistics of detailed cloud properties and now serves as a model for programs around the world (Clothiaux et al. 2000; Kollias et al. 2007; Illingworth et al. 2007).

The ACRF paradigm of long-term continuous measurements is essential to the enhancement and evaluation of climate models that must simulate the evolution of atmospheric properties for long continuous periods, from decades to centuries. This measurement approach permits unparalleled examination of atmospheric-process behavior and model-performance evaluation over extended periods and a wide range of meteorological conditions.

Obtaining aerial measurements supplement ground-based observations. Observations at fixed and mobile sites are supplemented periodically with observations from aircraft. These data have yielded insights into a range of science issues including the absorption of radiation by clouds (Valero et al., 2003), and detailed composition of aerosol (Ferrare et al. 2006) and cloud properties. Detailed cloud properties 
such as ice crystal sizes are critical because they dictate the life cycle of a cloud and its interaction with radiation. Airborne measurements obtained during ACRF field campaigns in the Arctic (McFarquhar and Cober 2004), the tropics (May et al. 2008), and midlatitudes (Mace et al. 2002) revealed new information about ice crystal sizes and shapes in various cloud types. These observations led to greatly improved techniques for retrieving cloud properties from the ground, and also revealed serious errors in the treatment of ice particle formation in models.

Developing a new paradigm for using observations to improve climate models. The detailed and comprehensive measurements obtained at the ACRF sites are critical for model evaluation and improvement. ARM scientists developed a unique process to bridge the gap between observations and GCMs in which a subset of ACRF observations are combined (Zhang et al. 2001) to provide input to a GCM, while other ACRF observations, such as cloud profiles, are used to evaluate the model's performance (Randall et al. 1996). This technique has led to specific improvements in GCMs, including the treatment of ice crystals in cirrus clouds (Liu et al. 2007).

Achieving significant improvement in water vapor measurements. While carbon dioxide is a key contributor to climate change, the dominant greenhouse gas in the Earth's atmosphere is water vapor. Using detailed ACRF measurements of water vapor and associated radiative transfer calculations, ARM scientists have reduced uncertainty in the measurement of water vapor from $13 \%$ to less than $4 \%$ during the past decade. This marked reduction has led to vastly improved estimates of water vapor absorption in radiative transfer models (Revercomb et al. 2003; Turner et al. 2004) that are now employed in many weather forecast models and GCMs used by the IPCC (Iacono et al. 2000; Morcrette et al. 2001).

Improving the representation of radiation in climate models. Scientists used ACRF observations to significantly improve calculations of the distribution of radiant energy in the atmosphere. These improvements are encapsulated in the Rapid Radiative Transfer Model. Because this model offers greater accuracy and efficiency, it has been incorporated into several climate and numerical weather prediction models. Advancements in radiation calculations in these global models have led to improved forecasts of temperature and humidity in the upper atmosphere (Morcrette 2001).

Providing unique observations of the radiative impact of aerosols. While the effect of greenhouse gases is well characterized in GCMs, uncertainty remains regarding the effect of aerosols, such as dust and smoke. This is particularly true regarding their effect on radiation transfer in the atmosphere-by redirecting incoming solar radiation back into space or by redirecting outgoing infrared radiation toward the surface. Extensive aerosol observations from the ACRF sites and ARM Mobile Facility have quantified the impact of aerosols on the radiation budget in diverse climatic regions (Ferrare et al. 2006). ACRF made the first column radiation absorption measurements of the impacts of Saharan dust (Slingo et al. 2006), which is known to have an impact on hurricane development.

Unraveling the impact of aerosols on clouds. The largest source of uncertainty associated with the radiative forcing of aerosols is their impact on the radiative properties of clouds. These effects include the modification of cloud particle size, cloud phase (liquid/ice), and the formation of precipitation. Recent studies by ARM scientists at multiple ACRF sites have shown that as much as $15 \%$ of the variability in cloud droplet sizes is due to aerosol effects (Feingold et al. 2006; Lubin and Vogelmann 2006; Kim et al. 2008; Penner et al. 2004). 
Providing detailed information about the effects of clouds on radiation. With the retrieval of cloud properties on a continuous basis and the improvement of radiative transfer models, scientists can now derive vertical profiles of radiative fluxes at the ACRF sites. Work in this area has provided a remarkably detailed data set for studying the redistribution of radiative energy in the atmosphere (Mace and Benson 2008) and makes it possible to evaluate cloud and radiative profiles in climate models (McFarlane et al. 2007).

Translating detailed atmosphere observations for climate modelers. Many ACRF instruments generate information that requires specialized skills to understand and apply. ACRF staff and collaborators in the research community are working together to take this complex information and generate simple physical parameters that are readily accessible by the climate modeling community. One recently developed product is the Cloud Modeling Best Estimate (CMBE) which combines a set of cloud observations from various ACRF instruments on a common grid. This product is expected to greatly facilitate the use of ACRF cloud data by climate modelers and has been adopted as a standard evaluation tool by the National Center for Atmospheric Research Community Atmosphere Model (CAM).

Implementing a major improvement in the radiative effects of clouds in GCMs. Climate models have a particularly difficult time representing complex cloud systems in a relatively coarse spatial domain. Examination of cloud fields observed at the ACRF sites, combined with efforts to represent the radiative effects of those cloud fields, led to the development of a new cloud radiation scheme adopted for use in several climate models and weather forecasting models (Räisänen et al. 2005, 2007; Mocrette et al. 2008).

Developing a revolutionary new approach to climate modeling. TheTypically, GCMs are run at a very coarse resolution due to the time and cost required to produce simulations at a finer scale. This approach is particularly problematic for accurately simulating cloud processes because they are so dynamic in both space and time. To improve model forecasts, ARM scientists developed the Multiscale Modeling Framework that embeds finer resolution cloud models into the GCM, replacing the complex equations formerly used to represent clouds (Khairoutdinov et al. 2001). This breakthrough nested-model approach, specific for clouds, was shown to successfully transfer the small-scale variability of cloud properties into the large-scale GCMs.

These contributions to climate change research would not be possible without the high quality, long-term data provided by the ACRF. The ARM website at www.arm.gov includes extensive information about the ACRF, further examples of ARM research, and a publications database which lists nearly 2000 peerreviewed journal articles whose authors have made use of the ACRF for climate research. 


\section{Contents}

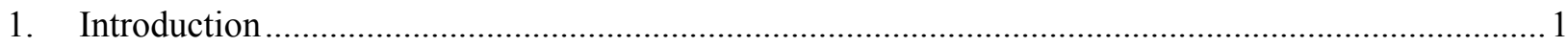

2. Parameterization of Climate Processes in Climate Models Are a Major Source of Uncertainty .......... 2

3. Many Climate Feedbacks, Especially With Respect to Clouds, Are Poorly Represented .................... 6

4. Uncertainty in Climate Forcing is Substantial, Especially That Relating to Aerosol Forcings ............ 9

5. Climate-Carbon Cycle Feedbacks Need to Be Better Quantified .................................................... 13

6. Changes in the Surface Energy Budget and its Links to the Hydrological Cycle ............................. 15

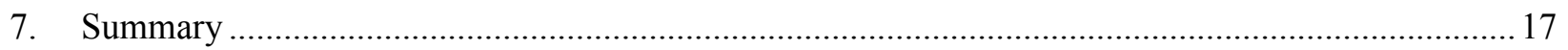

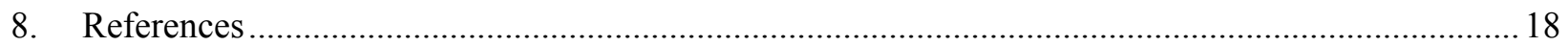




\section{Introduction}

In 1989, the U.S. Department of Energy (DOE) Office of Science created the Atmospheric Radiation Measurement (ARM) Program within the Office of Biological and Environmental Research (BER) to investigate the scientific uncertainties related to global climate change, with a specific focus on the crucial role of clouds and their influence on radiative feedback processes in the atmosphere. The scientific infrastructure established through the ARM Program was designated a national user facility by BER in 2003, called the ARM Climate Research Facility (ACRF), to provide these scientific capabilities to the global research community.

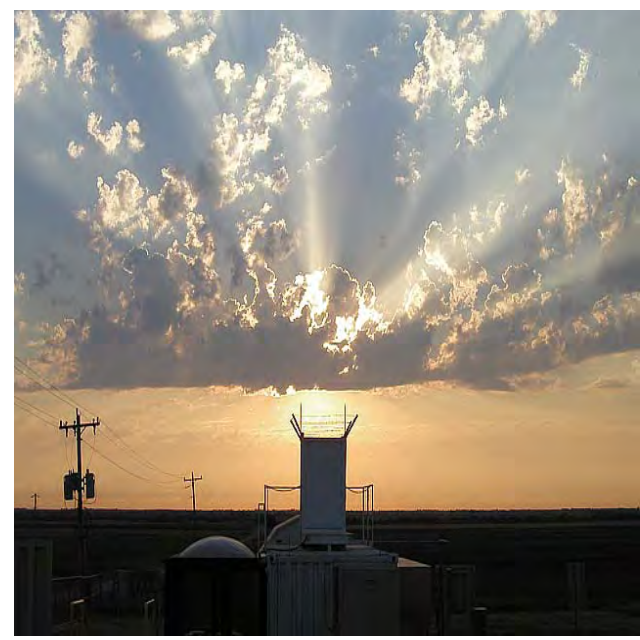

Scientific findings from the Atmospheric Radiation Measurement (ARM) Program and research conducted at the ARM Climate Research Facility have contributed more to understanding the crucial role of clouds and their influence on radiative feedback processes in the atmosphere than any other single research program in the world.
The ACRF consists of several highly instrumented ground stations, a mobile facility, and an aerial vehicles component for studying cloud formation processes and their influence on radiative transfer, and for measuring other parameters that determine the radiative properties of the atmosphere. The ground stations are located in three regions - the U.S. Southern Great Plains (SGP), the Tropical Western Pacific (TWP), and the North Slope of Alaska (NSA) - that were identified as representing a critical range of climate conditions that should be studied. This infrastructure and the resultant data archive is a valuable national and international asset available for use by scientists worldwide for advancing scientific knowledge of Earth systems.

The ACRF Archive contains more than 15 years of data from long-term monitoring at ACRF sites and from periodic field campaigns. This growing observational database has proved increasingly important in improving the representation of clouds and related processes in Global Climate Models (GCMs). Much of the early science effort in the ARM Program was devoted to understanding instrument performance, improving measurement accuracy, and developing methods to retrieve physical quantities of interest from the measurements. The program has now matured to the point that the data are now regularly used by modelers worldwide. The ACRF Archive is open and accessible to all national and international scientists and modelers and has become one of the greatest assets of the ARM Program.

During the past two decades, ARM scientists and the ACRF infrastructure have enabled major contributions to global observations, analyses, data, and knowledge related to the Earth's climate, the understanding of natural and anthropogenic causes of climate variability, and improvements in the projections of future climate change. In particular, ARM researchers have been primary contributors to improving knowledge of atmospheric composition and circulation and the role of clouds in modulating Earth's energy balance. 
The Intergovernmental Panel on Climate Change (IPCC) fourth major assessment (AR4) is a compilation of state-of-the-art of scientific knowledge on climate science today. Projections by GCMs for a range of emission scenarios, as described in the IPCC AR4 report, suggest that during the next few decades, a warming of about $0.2^{\circ} \mathrm{C}$ per decade is likely. The accuracy of GCMs must be improved both geographically and temporally to enable effective development of adaptation and mitigation plans at local and regional scales. Primary uncertainties in climate predictions as identified in the IPCC AR4 are shown in the table below.

\section{Primary Uncertainties in Predicting Climate Change}

- Parameterization of climate processes in climate models are a major source of uncertainty.

- Many climate feedbacks, especially with respect to clouds, are poorly represented.

- Uncertainty in climate forcing is substantial, especially that relating to aerosol forcings. And the full range of processes leading to modification of cloud properties by aerosols is not well understood and the magnitudes of associated indirect radiative effects are poorly determined.

- Climate-carbon cycle feedbacks need to be better quantified.

- Changes in the surface energy budget and its links to the hydrological cycle.

Research accomplishments by ARM scientists and other research at ACRF are summarized below in the context of each of these uncertainties.

\section{Parameterization of Climate Processes in Climate Models Are a Major Source of Uncertainty}

Poor parameterization of cloud processes is considered to be the main factor contributing to uncertainty in climate model projections. The contributions of ARM research toward advancements in global modeling are listed below, and further described in the following sections:

2a. Im proved parameterizations of radiative transfer

2b. Radiative transfer parameterizations for incorporating into GCMs

2c. Parameterization of vertical velocities in deep convection

$2 \mathrm{~d}$. Development of a climatology of atmospheric heating rate profiles at several locations

2e. Resolution of the cloud overlap problem

2f. Reduced uncertainties in characterization of deep convection

$2 \mathrm{~g}$. Improved accuracy of water vapor measurements.

2a. Improved parameterizations of radiation transfer

ACRF measurements and field campaigns have been central to improvements in the parameterization of the amount of longwave radiation absorbed by the water vapor 
continuum (Clough et al. 1989). These improvements, generally from small incremental changes, were made primarily in the water vapor self- and foreign-broadened continuum and the water vapor absorption line parameters. These changes, when taken as a whole, result in up to a $6 \mathrm{~W} / \mathrm{m} 2$ improvement in the modeled clear-sky downwelling longwave radiative flux at the surface and significantly better agreement with spectral observations (Soden et al. 2004). These reduced uncertainties have been encapsulated in the Rapid Radiative Transfer Model (RRTM). This model has been extensively tested against ARM data and is now considered to be a premier radiative transfer model.

2b. Radiative transfer parameterizations for incorporating into GCMs

The RRTM model exists in a reduced form (as RRTMG) for climate and weather models, and has been incorporated into a number of climate models, including the ECHAM5 ${ }^{1}$ climate model; the European Centre for Medium Range Weather Forecasts (ECMWF) and National Center for Environmental Prediction (NCEP) weather prediction models; the Weather Research and Forecasting (WRF) regional model; the National Center for Atmospheric Research (NCAR) MM5 mesoscale model; and the Arctic Regional Climate System model (Morcrette et al. 2001). Models that are testing

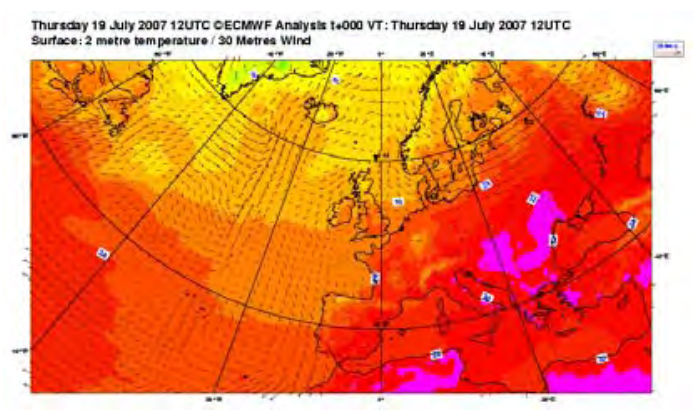

ECMWF analyses, like this one, now are more accurate thanks to new radiative transfer schemes developed through research supported by the ARM Program. RRTMG include the NCAR Community Atmosphere Model (CAM) and Geophysical Fluid Dynamics Laboratory (GFDL) climate models. RRTMG is likely to be incorporated into the CAM in the next few years (http://science.arm.gov/wg/cpm/scm/research/docs/ARM.Parameterizations.pdf).

2c. Parameterization of vertical velocities in deep convection

The intensity of moist convection is not currently predicted by most climate models, but is an important diagnostic of climate change. A parameterization of vertical velocities in deep convection was refined based upon observations from the Tropical Warm Pool - International Cloud Experiment (TWP-ICE). Soundings acquired during the experiment showed that the convective response to stronger large-scale forcing during the active monsoon period neutralized the moist stability. Except for "break" periods when occasional intense continental convection was occurring, sporadic moist convection under moderate forcing kept the mid-troposphere relatively cool, and, combined with the low-level heating from surface turbulent fluxes, led to a steeper lapse rate, generating more intense convection. When implemented into the Goddard Institute for Space Studies climate model, the refined parameterization was able to reproduce the common observation that deep convection is more intense over land than over ocean (Wu, Del Genio, and Wolf 2007). While the model predicts little change in the intensity of deep convection with global warming, the intensity of the strongest storms does increase.

\footnotetext{
${ }^{1}$ ECHAM is a comprehensive general circulation model of the atmosphere developed by the Max Planck Institute for Meteorology. ECHAM5 is the fifth generation of the model.
} 


\section{2d. Climatology of atmospheric heating rate profiles}

Clouds can have a major effect on the radiative heating of the atmosphere. To understand the influence of clouds, the radiative heating effect on the general circulation of the atmosphere and, in turn, changes in cloudiness must be understood. Ultimately a determination of the radiative heating of the atmosphere and related cloud feedback mechanisms are critically related to, among other factors, the accurate determination of cloud height in the column. Through a number of measurement programs and field campaigns, a climatology of atmospheric vertical heating rate profiles has been developed for the ACRF SGP site. Heating rate profiles are essential for testing radiation and cloud parameterizations in GCMs. Radiative heating rate profiles compute continuous vertical profiles of radiative heating for extended time periods at fixed sites. Profiles are available on a seasonal basis over many years for the SGP site (Mace et al. 2008; Mace and Benson 2005) and are also available (but for fewer years) for the NSA. Heating rate profiles are currently under development for the TWP. The long record (almost two decades) for the SGP site comprises a significant "climatology" of heating rate profiles at that site.

\section{2e. Resolution of cloud overlap problem}

Cloud parameterizations in GCMs make assumptions on how cloud layers are vertically arranged. These assumptions can have significant impacts on the radiation budget. Atmospheric dynamics have been shown to have a significant influence on cloud overlap, a factor that has been overlooked in some previous cloud parameterizations (Naud 2008). Because the horizontal resolution of GCMs is much coarser than the scale of clouds, GCMs parameterize the fractional area of a grid box that contains clouds. With cloud fraction determined at every vertical level of a GCM, this poses an uncertainty for radiative transfer.

The cloud radar record found in the ACRF Archive is now long enough to determine many cloud parameters, such as cloud overlap. The observational analyses show that clouds are maximally overlapped if the vertical distance separating two cloud layers is decreased (Hogan and Illingworth 2000; Mace and Benson-Troth 2002). Previously, GCMs simplified the cloud overlap issue by assuming that clouds in adjacent layers were maximally overlapped and clouds separated by clear layers were randomly overlapped. The new parameterization based on observational data from the ACRF is currently being adopted by several GCMs (Pincus et al. 2003). In addition, new methodologies have been developed by ARM scientists to represent this new cloud overlap parameterization statistically in GCMs, including CAM and ECHAM (Räisänen et al. 2005, 2007) and in ECMWF (Morcrette et al. 2008).

\section{2f. Reduced uncertainties in characterization of deep convection}

The GCM representation of deep convection is a parameterization with perhaps the greatest uncertainty of all. Representation of cumulus convection is an essential part of the feedback mechanisms that modulate climate. Comparing convection schemes against observations is difficult, partly because convection parameterizations are formulated in terms of parameters that have not been adequately observed, and partly because the schemes lack information about parameters that are more directly observable. 
The frequency of deep convection predicted by the NCAR single column model (SCM) at field sites has been far greater than that observed (Klein and Del Genio 2006). A number of ACRF field campaigns have been devoted to observing deep convection over the SGP site and the resultant data have provided new insights into how deep convection behaves. By analyzing years of observational data from the ACRF Archive, scientists were able to deduce a new convective trigger and closure parameterization, one that determines how much precipitation occurs in a given convective event (Xie and Zhang 2000; Xie et al. 2004).

Noticeable improvements in climate forecasts resulted from the new parameterization. One enabled a better representation of the "double" Intertropical Convergence Zone problem. Another replicated the reduced incidence of tropical cirrus clouds as a result of the greater inhibition applied to the deep convection parameterization. This modified convective trigger was implemented into the NCAR SCM (which is essentially an isolated column of a global climate model) and was shown to yield an improved simulation. The convective trigger has also been implemented into a Japanese global weather model (Xie and Zhang 2000).

\section{2g. Improved accuracy of water vapor measurements}

As the single largest percentage of greenhouse gases in the Earth's atmosphere, water vapor (or "humidity") is a critical component of climate change research. Because of its ability to absorb energy, water vapor plays an essential role in radiative feedback mechanisms and cloud formation. This is especially true in the upper troposphere - the highest point of weather conditions in Earth's atmosphere, at about 10-km high. At this altitude, small changes in moisture can significantly impact the amount of outgoing radiation, as well as influence the formation of ice-crystals in cirrus clouds.

For years, the radiation community has contended that, because water vapor dominates longwave radiative transfer, uncertainty in water vapor observations is the limiting factor in the improvement of longwave models. Through a series of water vapor field campaigns, ARM has developed multiple improvements in methods to measure water vapor. These include developing and improving both instruments and retrieval codes. Based on detailed comparisons among instruments and between measurements and models, the consensus is that scientists can now measure water vapor to better than $4 \%$ uncertainty. (Revercomb et al. 2003; Turner et al. 2003).

Long term water vapor measurement data stored at the ACRF Archive have been shown to be extremely valuable for many climate researchers. For example, a recent study of a 1-year data set of water vapor measurements obtained by a Raman lidar at the SGP site showed that ice supersaturation occurred about one-third of the time in cirrus clouds, confirming existing assumptions regarding the frequency of homogenous (non-aerosol related) cirrus formation (Comstock, Ackerman, and Turner 2004; Comstock 2007). Ice supersaturation also occurred during heterogeneous (aerosol-related) cirrus formation. This type of ice formation results in smaller ice particles, thereby increasing the resulting reflectivity of the cloud. This implies that heterogeneous formation may play a larger role in the impact of cirrus clouds on the Earth's radiative energy budget than previously thought. 
The long-term continuous data set provided by the ACRF Raman lidar allowed researchers to provide the first analysis of reliable upper tropospheric water vapor profiles measured from a single location (Soden 2004). These findings and the data set used to reach them represent an important link between the measurement and modeling communities as they continue to improve scientific understanding of the effect of cirrus clouds on the Earth's climate.

\section{Many Climate Feedbacks, Especially With Respect to Clouds, Are Poorly Represented}

Cloud feedbacks, particularly from low clouds, remain the largest source of uncertainty in climate models. Cryospheric feedbacks - feedbacks from perennially frozen surfaces, such as changes in snow cover - have been shown to contribute less to the uncertainty in model estimates of climate sensitivity than cloud or water vapor feedbacks, but they can be important for regional climate responses at mid- and high- latitudes. Models that enable exploration of changing feedbacks and predictions at regional to local scales can be helpful in evaluating trade-offs of different resource management and mitigation options. Cloud feedbacks are critical for this purpose and are the primary source of inter-model differences in equilibrium climate sensitivity, with low clouds being the largest contributor. Major field campaigns at the ACRF have allowed DOE-supported researchers to take the lead in attempting to observe and quantify land-surface cloud feedbacks.

ARM has made significant strides in the characterization of low clouds in the climate system through its long-term monitoring of these clouds at several sites, and in quantifying the radiative uncertainties associated with the occurrence of ultra-thin liquid clouds. However, large uncertainties still remain about how clouds might respond to global climate change. To address uncertainties in the characterizing climate feedback with respect to clouds in global models, the ARM Program has supported the below improvements, which are further described in the following sections:

3a. Development of a Multi-scale Modeling Framework

$3 \mathrm{~b}$. Fundamental revision in characterizing the modes of precipitation from convection

3c. Improved evaluation of cloud parameterizations in climate models

3d. Field campaign data to quantify land-surface cloud feedbacks.

3a. Development of a Multi-scale Modeling Framework

During the last few years, a new type of GCM has emerged in which a 2-dimensional or small 3 -dimensional cloud-resolving model (CRM) is embedded into each grid of a GCM. The embedded CRM removes the need for most of the cloud parameterizations used in traditional GCMs. This new approach is frequently called a Multi-scale Modeling Framework (MMF).

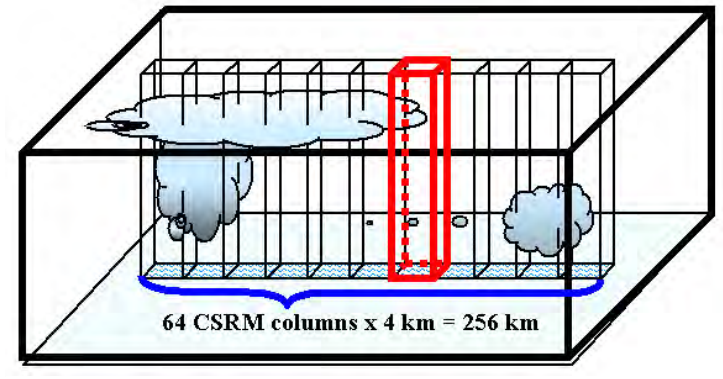

To address small-scale atmospheric processes, the Multi-scale Modeling Framework, or MMF, embeds a smaller cloud resolving model into each column of the larger global climate model. 
The conventional CAM overestimates the occurrence of cirrus clouds, leading to errors in predicting cloud feedback effect. The MMF, developed by ARM scientists (Randall et al. 2003; Khairoutdinov et al. 2005; Ovtchinnikov et al. 2006), replaces the parameterization of cumulus convection and other physical processes, such as large-scale condensation, radiation, and turbulence, with a low-resolution, 2-dimensional CRM. The new methodology was developed with seed money from the ARM Program, following the original idea of Grabowski of NCAR. Initial MMF simulations yielded an improved simulation of the Madden-Julian Oscillation and the diurnal cycle of precipitation over land-two features that are difficult for conventional climate models to simulate.

\section{3b. Characterizing modes of precipitation}

Cumulus convection is an essential part of the feedback mechanisms that modulate climate. However, representing cumulus convection in global models has been a long-standing challenge to the modeling community. The parameterization schemes used to produce convection in global models are often highly sensitive to key parameters and crude assumptions about complex microphysical processes. Comparing these schemes against observations is difficult, partly because convection parameterizations are formulated in terms of parameters that have not been adequately observed.

A large set of millimeter wavelength cloud radar (MMCR) observations from ARCF's tropical sites were used to relate MMCR reflectivity patterns to other properties of convective systems. A clustering analysis was used to categorize radar reflectivity patterns into distinct "storm classes," based on cloud and precipitation echo top heights, cloud layering, and the presence of precipitation. Rather than occurring in deep convective systems, precipitation was more commonly associated with multi-layered structures, often consisting of higher altitude cirrus overlying lower-level cumulus. The structures revealed by these radar data suggest a fundamental revision of what has typically been thought of as the modes of precipitation from convection. These results, based on observations at the ACRF sites, have profound implications for modeling tropical dynamics and the medium-range prediction of tropical variability.

\section{3c. Improved evaluation of cloud parameterizations in climate models}

While fair-weather clouds are small in size, they are ubiquitous, occurring over large areas of continents and in the trade wind regions over the oceans. These clouds play an important role in the Earth's climate by reflecting the sun's energy away from the planet. Fair-weather clouds are smaller than the grid spacing used in most numerical models of the atmosphere, making reliable parameterizations of these clouds very important to model performance.

Results from a study of 5 years of shallow fair-weather cloud statistics at the SGP site showed that cloud properties depend primarily on the time of day and the amount of lowaltitude moisture. In contrast to cloud fraction being largest for conditions with large lowaltitude moisture, the study showed that cloud-cover hours were largest for moderate values of low-altitude moisture. This finding indicates that clouds are less likely to form when conditions are moist, but when they do form, there are many clouds leading to a large cloud fraction. A new variable called "cloud-cover hours" was introduced to better account for the number of days and length of times with fair weather clouds. 
3d. Field campaign data to quantify land-surface cloud feedbacks

\section{Cloud LAnd Surface Interaction Campaign}

In June 2007, the Cloud LAnd Surface Interaction Campaign (CLASIC) took place, centered on the SGP site. The primary focus of the study was to evaluate how land surface processes influence the evolution of cumulus convection, especially the stages leading from cumulus humilis (fair weather clouds) to cumulus congestus (storm clouds), and to ascertain the relative contribution to regional precipitation of local water vapor versus water vapor advected into region. Cumulus convection is an important component in the atmospheric radiation budget and hydrologic cycle, particularly in the Southern Great Plains during the summertime growing season. Land surface changes associated with plowing, crop rotation, and irrigation can induce changes in the surface latent heat flux, sensible heat flux, albedo, and carbon flux. Changes in surface energy balance and moisture transport to the boundary layer influence cloud processes, thus creating a feedback loop.

Sponsored by DOE in cooperation with other agencies and several universities, researchers used aircraft, satellite, and enhanced surface-based instrument platforms to obtain simultaneous ground and airborne data. Measurements included those related to important hydrologic components in land-atmosphere interactions: soil moisture (the storage reservoir), evapotranspiration (the moisture supply to the atmosphere) and precipitation (the moisture supply to the ground). An increasing and high amount of soil moisture over most of the CLASIC domain was observed throughout the campaign, supporting the hypothesis of moisture recycling during CLASIC. Knowledge gained from this study is being applied to improved prediction tools that will benefit a broad spectrum of applications in agriculture ranging from more accurate weather forecasting to improved water management decisions and crop yield estimation.

\section{Convective and Orographically Induced Precipitation Study}

The Convective and Orographically Induced Precipitation Study (COPS) was conducted in the Black Forest region of Germany during 2007. The focus of the study was to advance the quality of forecasts of orographically-induced convective precipitation through 4-dimensional observations and life-cycle modeling. COPS was conducted through an extensive collaboration between research institutions from eight countries (Wulfmeyer et al. 2008). The ACRF provided the ARM Mobile Facility (AMF) and its extensive array of instruments to provide a previously unachieved data set on initiation of convection, as well as cloud and precipitation microphysical properties in a low-mountain region.

Orographic enhancement of precipitation in mountainous regions can result in severe flash flood events. Real-time, mesoscale data assimilation of key prognostic variables, such as water vapor and cloud dynamics, into advanced mesoscale models has the ability to significantly improve the forecasting for these regions. Data provided by the AMF during COPs will lead to improved prediction and quantification of precipitation, and an enhanced ability to forecast the likelihood of extreme weather events. 


\section{RAdiative Divergence using AMF, GERB and AMMA STations}

In 2006, the AMF was deployed in Niamey, Niger, through the ACRF campaign, RAdiative Divergence using AMF, GERB and AMMA Stations, or RADAGAST. This campaign was part of a large, multiyear international field program, titled the African Monsoon Multidisciplinary Analyses (AMMA) Project. RADAGAST was designed for the AMF to supply continuous measurements of the broad-band upward and downward solar and thermal radiative fluxes at the surface. When combined with corresponding measurements from the Geostationary Earth Radiation Budget (GERB) instrument on a European satellite, these measurements provide the first well-sampled direct estimates of the energy balance across the atmosphere. To date, many GCMs have been unable to simulate the West African monsoon due to the complex interactions between the atmosphere, the biosphere, and the hydrosphere, and the related life cycles of the associated rain producing systems. RADAGAST played a major role in linking multiscale observations, data analysis, and modeling to improve the ability of both weather and climate models to predict the formation and dynamics of the West African monsoon.

The African monsoon differs from the Asian monsoon in that it is less resilient to changes resulting from interannual global climate system variability. This has led to long periods of drought in West Africa. The current drought has lasted more than 30 years, with serious social and health implications for the countries in the region. The African monsoon is important for other reasons as well. There is a significant correlation between Atlantic hurricanes and West Sahelian rainfall, and there is strong evidence that the African monsoon region is critical in the emission of ozone precursors and aerosols and their redistribution over the global troposphere.

The AMMA observing periods included several years of extensive measurements of the atmospheric dynamics, atmospheric chemistry, continental water cycle, and land surface conditions of the region; the RADAGAST campaign contributed 1 year of data to this effort. Early results from the campaign showed significant land surface radiative effects (Lamb et al. 2008) and dry season dust generation over Niamey correlated with low-level northeasterly wind surges associated with cold fronts moving across the Sahara. The suspended dust has significant impacts on near surface visibility and high-altitude humidity, and can influence the occurrence of rainfall events. Data from AMMA are expected to provide valuable constraints for the testing of mesoscale updraft and stratiform anvil parameterizations that are currently absent from or deficient in GCMs.

\section{Uncertainty in Climate Forcing is Substantial, Especially That Relating to Aerosol Forcings. And the full range of processes leading to modification of cloud properties by aerosols is not well understood and the magnitudes of associated indirect radiative effects are poorly determined.}

An important uncertainty in understanding aerosol effects on climate is the interactions between clouds and aerosols. In the last decade, ACRF incorporated a wide range of instrumentation for measuring aerosol at its fixed sites and as part of the mobile facility and aerial vehicles. ARM research has improved the understanding of how anthropogenic and natural aerosols influence cloud formation, cloud properties, cloud lifetime, and 
precipitation physics. This new understanding is leading to the development of improved parameterizations in GCMs, as noted below and further described in the following sections.

4a. The first observational evidence of indirect aerosol impacts on clouds in specific location and under specific conditions

4b. A fundamental unifying model for the autoconversion rate in warm clouds that includes the impact of the underlying aerosol distribution

4c. Modification of radiative properties of low liquid clouds due to anthropogenic aerosols

4d. Publication of the first radiative absorption estimates from a dust storm in West Africa

4e. Observations showing that direct aerosol forcing can be affected dramatically by cloudiness

4f. New parameterizations of cloud and aerosol interactions for climate models

4g. A new theoretical formulation to characterize mixed-phase clouds and the growth of cloud droplets.

4a. The first observational evidence of indirect aerosol impacts on clouds

The first aerosol indirect effect of suspended atmospheric particles on the microphysics of clouds occurs when an increase in the number of aerosol or cloud condensation nuclei $(\mathrm{CCN})$ within a cloud decreases the average cloud droplet size, hence reflecting more energy to space. During May 2003, a field campaign was conducted at the SGP site to measure the radiative effects of aerosol and clouds. Both in situ and remote sensing instruments were available to measure aerosol and cloud parameters. The measurements confirmed the presence of the first aerosol indirect effect. Also known as the "Twomey" effect, this causes higher aerosol number concentration and smaller mean droplet size, enhancing cloud reflectivity. Results from the campaign showed that the methodology used for retrieving droplet size and the proxy used for aerosol, or CCN, concentration strongly affected the magnitude of the drop size response to changes in aerosol. These findings indicated the need for additional work to determine the most suitable proxies for $\mathrm{CCN}$ and the most appropriate drop size retrieval method.

At the NSA site, observations have shown that enhanced aerosol concentrations cause cloud droplets to be smaller and more numerous within clouds of fixed water amount, the first aerosol indirect effect. A 6-year analysis at the NSA site found that this process can make clouds more opaque, causing them to emit more thermal energy to the surface. This insight is significant for understanding the Arctic energy balance (Lubin and Vogelmann 2006).

4b. A fundamental unifying model for the autoconversion rate in warm clouds that includes the impact of the underlying aerosol distribution

A key process that must be parameterized in atmospheric models of various scales - from large eddy simulation models to cloud resolving models to GCMs - is the autoconversion process. In this process, large cloud droplets collect small ones and become "embryonic" raindrops. Accurate parameterization and physical understanding of this process is especially important for studies of the second aerosol indirect effect, when microphysical changes caused by the first aerosol indirect effect inhibit or slow down precipitation formation, and thereby increase the cloud liquid water path (LWP) and cloud lifetime. A new type of 
parameterization was developed (Liu et al. 2007) by coupling the threshold function that describes the onset of the autoconversion process, with expressions for the rate function and critical radius. The new parameterization eliminates many deficiencies of prior treatments of the process.

4c. Modification of radiative properties of low liquid clouds due to anthropogenic aerosols In cases of thin warm stratocumulus clouds, increased aerosols lead to increased cloud droplet number concentration, providing increased surface area of droplets where water vapor condenses. This increases condensation, and thus condensational heating, producing stronger updrafts and leading to an increased LWP with increased aerosols in cases where precipitation reaches the surface (Lee and Penner 2008). In a case with no surface precipitation, LWP decreases with increases in aerosols. In this case, most precipitation evaporates just below the cloud base. With decreasing aerosols, precipitation increases and leads to increasing evaporation, thereby increasing instability around cloud base.

Thin clouds with mean LWP of $\sim 50 \mathrm{~g} / \mathrm{m} 2$ cover $27.5 \%$ of the globe, thus playing an important role in the Earth's radiation budget. Radiative fluxes at the Earth's surface and top of atmosphere (TOA) are very sensitive to LWP variation when the LWP becomes smaller than $\sim 50 \mathrm{~g} / \mathrm{m} 2$. This indicates that aerosol effects on thin clouds can have a substantial impact on the variation of global radiative forcing if LWP changes.

4d. The first radiative absorption estimates from a dust storm in West Africa

The results of the previously described 2006 field campaign (see 1.d above) in Niamey, Niger, yielded the first measurements of radiation absorption by aerosols, primarily dust and smoke, in that region. It was shown that dry season aerosols exhibited different characteristics when compared to wet season aerosols, and that the characteristics of a dustladen aerosol are quite different from a smoke-laden aerosol. Past studies found that mineral dust in the atmosphere can contribute to direct radiative forcing and potentially to tropical cyclogenesis. The role of dust clouds in influencing the climatology of West Africa is extremely important because the genesis of tropical waves from this region may have a relationship to the formation of hurricanes that can travel across the Atlantic and impact the southern United States. Further study of the data from the RADAGAST campaign is underway to fully assess the implications of the Niamey dust storms



In March 2006, the ARM Mobile Facility and satellite instruments made the first simultaneous observations of a major dust storm from space and the ground, allowing researchers to test their understanding of how dust affects the radiant energy budget of the atmospheric column. (Slingo 2006).

4e. Observations showing that direct aerosol forcing can be affected dramatically by cloudiness 
Direct aerosol forcing can be affected dramatically by cloudiness. Research at the ACRF has shown that the sign of aerosol forcing can change to positive (thereby increasing the overall forcing) in cases where there is a high surface albedo, such as over clouds and snow. A comparison of aerosol studies at the different ACRF sites show a major difference in forcing efficiency depending on site conditions.

For example, there are considerably greater differences in the forcing efficiency between a generic maritime ocean model $(-35 \mathrm{~W} / \mathrm{m} 2)$ and efficiencies observed at the TWP site during the time of year when significant biomass burning occurs $(-48 \mathrm{~W} / \mathrm{m} 2)$ (Mather and McFarlane 2008; Mather et al. 2007). These results suggest that anthropogenic aerosols, such as those from biomass burning, can significantly influence the radiative properties of oceanic aerosols. This influence alters their properties considerably from those for generic, pristine ocean aerosol models that may be used in climate models. Further, given the potential longrange transport of these aerosols, these radiative effects can extend to regional, and possibly global, scales. More attention will be needed to develop methods for ascertaining the properties of oceanic aerosols so that they may be treated properly in models.

Recent research has also shown that for low-level clouds, aerosols do affect cloud properties relative to the initial aerosol concentration. Scientists used data from low-level clouds at the SGP and NSA sites to compare direct observations of high- and low-aerosol environments with simulations from a simple parcel model. By sampling a wide variety of atmospheric conditions, researchers investigated aerosol effects on cloud properties. The results show that aerosols do impact cloud properties in significant and quantifiable ways. By reviewing 6 years of data at the NSA site, it was found that the indirect effects of aerosols can make clouds more opaque and emit more thermal energy to the surface. This finding has significant implications for cloud feedbacks in the Arctic (Penner et al. 2004).

\section{4f. New parameterizations of cloud and aerosol interactions}

At one time, many global models neglected to include the effects of indirect aerosol forcing from the nucleation of droplets within clouds. Researchers funded by the ARM Program developed a treatment of droplet nucleation and applied it to the CAM. In coupling the droplet nucleation scheme with aerosols in CAM, the simulated energy balance of the climate - a critical measure of model performance - is very close to the energy balance simulated with droplet number prescribed at a distribution of highly tuned values. This agreement also holds when the dependence of droplet "autoconversion" (merging of droplets - a key process for precipitation formation) on droplet number is treated.

Parameterizations of aerosol forcing have been tested in ARM SCM simulations with a modified version of the NCAR SCM and shown to produce sensitivities to aerosols similar to those simulated by a CRM, which should be expected to produce a more realistic simulation of this effect (Ovtchinnikov and Ghan 2005). These parameterizations were also tested in CAM3. $0^{2}$ and produced a realistic simulation of the mean climate (Ghan 2004).

\footnotetext{
${ }^{2}$ The CAM 3.0 is the fifth generation of the NCAR atmospheric GCM, originally known as the Community Climate Model, or CCM.
} 
Simulations incorporating improved parameterizations of the size and shape distributions of ice crystals into the Scripps SCM (McFarquhar et al. 2003 and Iacobellis et al. 2003) over the TWP and SGP have shown that the variability in particle sizes and scattering properties can sometimes play a greater role in cloud-radiation interactions than the more obvious changes in the parameterizations themselves. Further, differences in longwave heating rates, predicted by the different microphysical parameterizations, feed back upon the cloud water content. This in turn affects the cloud radiative forcing in a way that either amplifies or reduces the change in cloud radiative forcing that is directly associated with a modification of the microphysical or single-scattering properties. These findings have important ramifications for the way future parameterizations of cloud-radiation interactions should be developed.

4g. A new theoretical formulation to characterize mixed-phase clouds and the growth of cloud droplets

The total mass of water condensed into clouds is controlled by thermodynamics. Therefore, a greater number of droplets for the same mass of cloud water cause the average size of the cloud droplets to be smaller. This has two important effects. First, smaller drops lead to more reflective clouds, which tend to cool the climate system. Second, smaller droplets are less likely to produce drizzle or rain. As a result, the cloud will "live" longer, which also tends to produce a cooling of the system. The degree to which these effects occur in nature is a topic of great uncertainty.

The process of autoconversion, whereby cloud droplets grow into embryonic raindrops, must be accurately represented in atmospheric models in order to predict precipitation and climate correctly. Until recently, simplified schemes which predict only the cloud liquid water content have been used in climate models. These schemes, among other deficiencies, are incapable of dealing with indirect effects of aerosols. A few models use more sophisticated parameterizations, but these are empirical in nature, with little theoretical basis.

ARM researchers were among the first to test a prognostic representation of cloud droplet number - including a treatment for ice crystal number — in a climate model (Ghan et al. 1997; Penner et al. 2004). A new theoretical formulation was developed and tested using ACRF data collected during the Mixed-Phase Arctic Cloud Experiment (M-PACE) at the NSA site. The new parameterizations worked well when implemented into the CAM, and are being combined with other treatments of aerosol-cloud interactions that are likely to be included into the next release of the CAM (see http://science.arm.gov/wg/cpm/scm/research/docs/ARM.Parameterizations.pdf).

\section{Climate-Carbon Cycle Feedbacks Need to Be Better Quantified}

As the temperature of the atmosphere increases, warmer soils decompose faster and release more carbon dioxide. Warmer oceans also release more carbon dioxide, but scientists have yet to fully quantify the full impact of these feedback processes. The broad range of models now available suggests climate-carbon cycle feedbacks are more important than originally thought. In one IPCC scenario, for example, the climate-carbon cycle feedback increased the corresponding global average warming by the year 2100 by more than $1^{\circ} \mathrm{C}$. Research based on ACRF observations have contributed to a better understanding of carbon cycle feedbacks by: 
5a. Establishment of a coordinated carbon measurement network in the Southern Great Plains to link regional greenhouse gas budgets to surface fluxes and atmospheric dynamics

5b. Facilitating calibration of the NASA Orbiting Carbon Observatory

5c. Recording the effects of vegetation changes on carbon fluxes.

5a. Establishment of a coordinated carbon measurement network in the Southern Great Plains to link regional greenhouse gas budgets to surface fluxes and atmospheric dynamics

The ACRF has incorporated a program for carbon cycle research at the SGP site with precise carbon dioxide $\left(\mathrm{CO}_{2}\right)$ concentrations and flask sampling from the SGP Central Facility tower and from weekly plane flights above the planetary boundary layer. These tie the SGP region into the global atmospheric measurement networks and provide the mid-continent anchor for national and international greenhouse gas mappings. The long-term precise $\mathrm{CO}_{2}$ record shows that although anthropogenic sources give this site higher than background concentrations, the annual rate of increase is the same as that in marine background sites. Data collected at the site have the potential to further improve estimates of carbon cycle fluxes and pools affected by exchanges between the atmosphere and the land surface, especially vegetation, soil, and detritus.

In addition to standard meteorological forcing variables, ACRF site radiation measurements reflect parameters which affect vegetation and

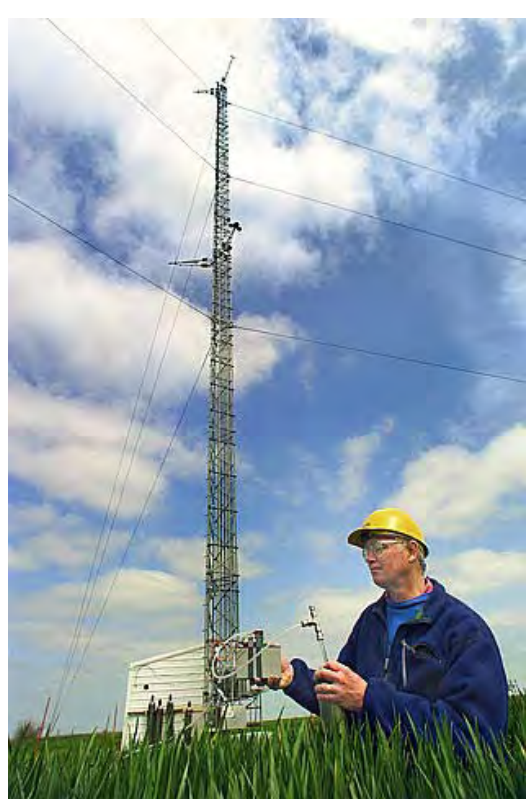

Gas samples collected in the wheat fields surrounding the base of the 60-m tower at the SGP site are key to ongoing carbon cycle research. decomposition. ACRF data provides measured rather than estimated meteorological data which can be used to "drive" carbon cycle simulations of photosynthesis, respiration, decomposition, and other important carbon fluxes. Research has shown that there is enough carbon stored in soils for soil flux to the atmosphere to be an important component of the global carbon cycle. Changes in temperature, moisture, and vegetation are likely to cause changing carbon fluxes from the land surface in the coming decades.

Other useful data for carbon modeling provided through the ACRF includes measurements of soil moisture and temperature through a depth profile, as part of the Soil Water and Temperature System instruments. A number of eddy correlation flux measurement systems containing carbon sensors are deployed at the SGP site, contributing substantially to carbon flux towers presently available to carbon researchers in the Ameriflux network. Carbon research at the ACRF includes studies to (1) link atmospheric $\mathrm{CO}_{2}$ levels with energy and water fluxes from the land surface; (2) predict interannual and long-term carbon fluxes; (3) assess the impact of land use and disturbance on carbon sequestration; and (4) conduct inverse carbon modeling by providing new data on net fluxes and isotopic signatures. Ground-based and airborne instruments are engaged in flask-based collection of trace gases 
by sampling $\mathrm{CO}, \mathrm{CH} 4,13 \mathrm{CO}_{2}$, and $14 \mathrm{CO}_{2}$ at various heights to provide, with the $\mathrm{CO}_{2}$ profiles, comprehensive data for inverse methods that infer ecosystem carbon exchange and quantify anthropogenic combustion emissions.

5b. Calibration of the NASA Orbiting Carbon Observatory

Carbon dioxide concentration profiles from the surface to mid-troposphere (i.e., 5-7 km) are being measured at two ACRF sites to facilitate calibration of the NASA Orbiting Carbon Observatory (OCO) and inform models to close carbon budgets. These measurements are providing valuable data for addressing carbon-cycle questions highlighted by the U.S. Climate Change Research Program and the North American Carbon Program.

5c. Carbon fluxes measured during a recent major field campaign are yielding information about the effects of vegetation changes on carbon fluxes

One goal of CLASIC (also see section 2d. above) in 2007 was to evaluate top-down and bottom-up regional carbon fluxes and to understand the influence of moisture gradients, vegetation changes, surface heterogeneity, and atmospheric transport on these fluxes estimates. $\mathrm{CO}_{2}, \mathrm{CO}, \mathrm{CH}_{4}$, and carbon isotope concentration data were collected from tower and airborne platforms throughout a 4-week period. As expected, higher $\mathrm{CO}_{2}$ concentrations were observed over urban areas. Aircraft moving from urban to agricultural areas measured decreasing $\mathrm{CO}_{2}$ concentrations by $\sim 2 \mathrm{ppm}$, reflecting the regional photosynthetic activity of vegetation (Biraud et al. 2008). Combining ACRF $\mathrm{CO}_{2}$ measurements, satellite observations, and land-surface modeling have led to a better understanding of the impact of resolution on regional-scale surface energy fluxes and net ecosystem exchange estimates.

\section{Changes in the Surface Energy Budget and its Links to the Hydrological Cycle}

Clouds play a major role in the processes that affect the hydrological cycle and all relevant feedback mechanisms that alter its response to external climate forcing. This is especially true in the tropics, where the convergence of moist air along the equator results in convection that creates the deepest clouds, the heaviest rainfall, and the largest release of latent heat on the planet. Because of the vigorous feedbacks that contribute to these conditions, tropical intraseasonal variability has proven difficult to simulate, and even more difficult to predict.

Research at the ACRF is relevant to better understanding the hydrologic cycle, and includes the below achievements, which are then described in more detail.

6a. Evaluating land-surface interactions and improving land-surface models

6b. The role of mixed-phase clouds in the energy budget of the Arctic. 
6a. Evaluating land-surface interactions and improving land-surface models

The long record of measurements made at ACRF sites related to the surface energy budget has been extensively used by many scientists, both nationally and internationally, especially in evaluating land-surface models.

More than a decade of data on the surface radiation budget exists from ACRF sites. These data cover radiative, latent, and sensible heat measured by ARCF radiometers and other methods such as the energy balance bowen ratio station and the eddy correlation flux measurement system. Surface heat flux data are among the most heavily used in the ACRF Archive. One user of ACRF land-surface data is the North American Land Data Assimilation System (NLDAS), a multi-institutional project focusing on providing accurate values of land surface conditions by combining — or "assimilating"—observed atmospheric data into models focused on predicting the observed conditions. Especially useful to NLDAS are data related to warm season precipitation, one of the most difficult variables to accurately forecast.

Comparisons of land-surface models against observed measurements found that the models were inconsistent - some overestimated measurements while others underestimated them - in almost every category except for soil temperature (Robock et al. 2003). Measurement categories included soil temperature and moisture at varying depths, precipitation, and both incoming and outbound radiative fluxes in short- and long-wavelengths. The amount of water in the soil at any time and its availability to plants can have a major effect on surface energy fluxes and hence, on local atmospheric and hydrological conditions. The model comparison found many discrepancies related to soil information, which varies continuously as any one land surface point in a model may contain a variety of soil types. Comparing model performance to observations helps to evaluate the effectiveness of modifications to computer model parameterizations. Once proven for weather forecasting, improvements in the parameterizations can also be applied to climate simulations.

6b. The role of mixed-phase clouds in the energy budget of the Arctic

Clouds play a particularly important role for the surface energy balance in the Arctic and are difficult to model. Several recent studies suggest that the Arctic climate is more sensitive to changes in climate forcing than other regions on Earth, while global climate models are less reliable in this region (ACIA 2004). Data from M-PACE successfully documented the microphysical structure of Arctic mixed-phase clouds (Verlinde et al. 2007). The large number of ice crystals measured during M-PACE could not be explained with known ice formation mechanisms. This suggests that current representations of ice microphysics in largescale numerical weather prediction and


Data from M-PACE allowed researchers to compare models against observations of mixedphase clouds, revealing a tendency for models to predict enhanced climate feedbacks. 
global climate models may lack representation of some of the dominant ice formation mechanisms. The formation of ice nuclei from drop evaporation residuals or drop freezing during evaporation might explain excess ice formation in these clouds (Fridlind et al. 2007).

More complicated ice microphysical parameterization schemes, including one that considers the sensitivity of Arctic mixed-phase clouds to changes in aerosols, should be used to describe the processes occurring and to provide optimum agreement with observed fields (Luo et al. 2007). The data are now being used to evaluate retrievals of cloud properties and radiative heating profiles derived from the ACRF ground -based sensors.

\section{Summary}

The $4^{\text {th }}$ IPCC assessment reported that confidence in global climate models has increased due to the following:

- improvements in the simulation of many aspects of present climate, including important modes of climate variability and extreme hot and cold spells;

- improved model resolution, computational methods and parameterizations and inclusion of additional processes;

- more comprehensive diagnostic tests, including tests of model ability to forecast on time scales from days to a year when initialized with observed conditions; and

- enhanced scrutiny of models and expanded diagnostic analysis of model behavior facilitated by internationally coordinated efforts to collect and disseminate output from model experiments performed under common conditions.

Research conducted by the ARM Program has played a large role in contributing to each of the areas above. In particular, the ACRF Archive holds data sets of great value to the modeling community. A number of tools allow ACRF Archive users to view and plot specific user-defined data to assist with selecting specific data sets for application in climate model evaluation. Of particular note are the existing multi-year observations of the effects of clouds on the surface radiation budget and the vertical distributions of cloud occurrence and emerging observations of cloud microphysics - cloud water mass and characteristic cloud drop sizes. In combination with the SCM forcing data sets which are being extended in time, scientists can now test new parameterization ideas and rule out unrealistic cloud parameterizations. It is expected that the next few years will yield many more examples of climate model improvements.

The IPCC report also notes this key uncertainty in the modeling area:

"A proven set of model metrics comparing simulations with observations that might be used to narrow the range of plausible climate projections has yet to be developed."

Producing these model metrics is a major goal of the ARM Program. Currently, products at the ACRF Archive include continuous estimates of daylight clear-sky, direct and diffuse shortwave radiation, plus fractional sky cover. These quantities allow assessment of radiative impact of clouds at the surface. To better serve the needs of climate model development, the ACRF has devoted significant effort to assemble a "climate modeling best estimate" (CMBE) of the highest 
quality cloud and radiation measurements. This data set, specifically tailored for use in evaluating of global climate models, includes long-term best estimates from selected ACRF measurements for cloud fraction, total cloud cover, shortwave and longwave radiation fluxes, LWP, and precipitable water vapor. These quantities are derived from three specialized algorithms and the total sky imager measurements. The current version of this data set contains data averaged over 1-hour time intervals from the ACRF sites in Barrow, Alaska; Nauru Island; Manus Island, Papua New Guinea; Darwin, Australia; and the SGP site.

Research at the ACRF and ARM science have contributed more to understanding the crucial role of clouds and their influence on radiative feedback processes in the atmosphere than any other single research program in the world. As the influence of clouds on climate has been consistently called out as the most significant uncertainty in climate modeling, the ARM Program has provided an immensely valuable service to the scientific community through its support of this research.

\section{References}

Ackerman, T, and G Stokes. 2003. "The Atmospheric Radiation Measurement Program. Physics Today 56:38-45.

Arctic Climate Impact Assessment (ACIA). 2004. Impacts of a Warming Arctic: Arctic Climate Impact Assessment. Cambridge University Press, 1020 pp.

Biraud, SC, WJ Riley, ML Fischer, MS Torn, D Billesbach, JA Berry, A Hirsch, C Sweeney, M Lowenstein, J Lopez, and R Avissar. 2008. "Regional carbon fluxes and atmospheric carbon dynamics in the Southern Great Plains during the 2007 CLASIC." Presented at the Eighteenth Atmospheric Radiation Measurement (ARM) Science Team Meeting, ARM-CONF-2008, March, Norfolk, Virginia.

Clough, SA, FX Kneizys, and RW Davies. 1989. "Line shape and the water vapor continuum." Atmospheric Research 23:229-241.

Comstock, J, R-F Lin, DO'C Starr, and Z Wang. 2007. "Understanding ice supersaturation and particle growth in cirrus clouds." Presented at the Seventeenth Atmospheric Radiation Measurement (ARM) Science Team Meeting ARM-CONF-2007, March, Monterey, California.

Comstock, JM, TP Ackerman, and DD Turner. 2004. "Evidence of high ice supersaturation in cirrus clouds using ARM Raman lidar measurements." Geophysical Research Letters doi:10.1029/2004GL019705.

Comstock, JM, R d'Entremont, D DeSlover, GG Mace, SY Matrosov, SA McFarlane, P Minnis, D Mitchell, K Sassen, MD Shupe, DD Turner, and Z Wang. 2007. "An Intercomparison of Microphysical Retrieval Algorithms for Upper Tropospheric Ice Clouds." Bulletin of the American Meteorological Society 88: 191-204. 
Ferrare, R, G Feingold, S Ghan, J Ogren, B Schmid, SE Schwartz, and P Sheridan. 2006. "Preface to special section: Atmospheric Radiation Measurement Program May 2003 Intensive Operations Period examining aerosol properties and radiative influences." Journal of Geophysical Research 111.

Fridlind AM, AS Ackerman, G McFarquhar, G Zhang, MR Poellot, PJ DeMott, AJ Prenni, and AJ Heymsfield. 2007. "Ice properties of single-layer stratocumulus during the Mixed-Phase Arctic Cloud Experiment: 2. Model results." Journal of Geophysical Research D: Atmospheres 112: Art. No. D24202, doi:10.1029/2007JD008646.

Ghan, SJ, LR Leung, RC Easter, and H Abdul-Razzak. 1997. "Prediction of cloud droplet number in a general circulation model." Journal of Geophysical Research D: Atmospheres 102(D21):21,777-21,794.

Ghan, SJ. 2004. "Prediction of cloud droplet number in CAM." Presented at the 2004 Spring Meeting of the NCAR Atmosphere Model Working Group, March 9-10, Boulder, Colorado.

Hogan, RJ, and AJ Illingworth. 2000. "Deriving cloud overlap statistics from radar." Quarterly Journal of the Royal Meteorological Society 126 (569):2903-2909.

Illingworth, AJ, RJ Hogan, EJ O'Connor, D Bouniol, ME Brooks, J Delanoë, DP Donovan, JD Eastment, N Gaussiat, JWF. Goddard, M Haeffelin, HK Baltink, OA Krasnov, J Pelon, JM Piriou, A Protat, HWJ. Russchenberg, A Seifert, AM Tompkins, GJ van Zadelhoff, F Vinit, U Willén, DR Wilson, and CL Wrench. 2007. "Cloudnet." Bulletin of the American Meteorological Society 88, 883-898.

Khairoutdinov, MF, and DA Randall. 2001. "A Cloud Resolving Model as a Cloud Parameterization in the NCAR Community Climate System Model: Preliminary Results." Geophysical Research Letters. 28: 3617-3620.

Khairoutdinov, M, D Randall, and C DeMott. 2005. "Simulations of the atmospheric general circulation using a cloud-resolving model as a superparameterization of physical processes." Journal of the Atmospheric Sciences 62:2136-2154.

Klein, SA, and AD Del Genio. 2006. ARM's Support for GCM Improvement: A White Paper. U.S. Department of Energy. DOE/SC-ARM/P-06-012, Washington, D.C.

Klein, SA, X Jiang, J Boyle, S Malyshev, and S Xie. 2006. "Diagnosis of the summertime warm and dry bias over the U.S. Southern Great Plains in the GFDL climate model using a weather forecasting approach." Geophysical Research Letters 33, L18805, doi:10.1029/2006GL027567

Kollias, P, EE Clothiaux, MA Miller, BA Albrecht, GL Stephens, and TP Ackerman. 2007: "Millimeter-Wavelength Radars: New Frontier in Atmospheric Cloud and Precipitation Research." Bulletin of the American Meteorological. Society 88, 1608-1624. 
Lamb, PJ, AB Mohamed, M Miller, IS Sanda, H Hama, and AA Adam. 2008. "Analysis of the AMF 2006 Niamey radiosonde data: Some preliminary results." Poster presentation at the Eighteenth Atmospheric Radiation Measurement (ARM) Science Team Meeting, ARM-CONF2008, March, Norfolk, Virginia.

Lee, S, and J Penner. 2008. "Dependence of aerosol-cloud interactions on environmental conditions." Poster Presentation at the Eighteenth Atmospheric Radiation Measurement (ARM) Science Team Meeting, ARM-CONF-2008, March, Norfolk, Virginia.

Liu, X, J Penner, S Ghan, and M Wang. 2007. "Inclusion of ice microphysics in the NCAR Community Atmospheric Model Version 3 (CAM3)." Journal of Climate 20, 4526-4547, doi: 10.1175/JCLI4264.1.

Liu Y, PH Daum, RL McGraw, MA Miller, and S Niu. 2007. "Theoretical expression for the autoconversion rate of the cloud droplet number concentration." Geophysical Research Letters 34: Art. No. L16821, doi:10.1029/2007GL030389.

Lubin, D, and A Vogelmann. 2006. "A climatologically significant aerosol longwave indirect effect in the Arctic." Nature 439(7075):453-456, doi:10.1038/nature04449.

Luo, Y; KM Xu, H Morrison, G McFarquhar. 2008. “Arctic Mixed-Phase Clouds Simulated by a Cloud-Resolving Model: Comparison with ARM Observations and Sensitivity to Microphysics Parameterizations." Journal of the Atmospheric Sciences, 64:4, pp. 1285-1303.

Mace, GG, and S Benson. 2008. "The vertical structure of cloud occurrence and radiative forcing at the SGP ARM site as revealed by 8 years of continuous data." Journal of Climate 21:2591-2610.

Mace, GG, S Benson, and S Kato. 2006. "Cloud radiative forcing at the Atmospheric Radiation Measurement Program Climate Research Facility: 2. Vertical redistribution of radiant energy by clouds." Journal of Geophysical Research D: Atmospheres 111(D11): Art. No. D11S91, doi:10.1029/2005JD005922.

Mace, GG, and S Benson-Troth. 2002. "Cloud-layer overlap characteristics derived from longterm cloud radar data." Journal of Climate 15(17):2505-2512.

Mace, GG, AJ Heymsfield, and MR Poellot. 2002. "On retrieving the microphysical propertieis of cirrus clouds using moments of the millimeter-wavelength doppler spectrum." Journal of Geophysical Research 107: doi:10.1029/2001JD001308.

Mather, JH, and SA McFarlane. 2008. "Radiative heating profiles at the ARM climate research facility TWP sites for radar-based cloud classes." Poster presentation at the Eighteenth Atmospheric Radiation Measurement (ARM) Science Team Meeting ARM-CONF-2008, March, Norfolk, Virginia.

Mather, JH, SA McFarlane, MA Miller, and KL Johnson. 2007. "Cloud properties and associated radiative heating rates in the Tropical Western Pacific." Journal of Geophysical Research D:

Atmospheres 112(D5): Art. No. D05201. 
May, PT, JH Mather, G Vaughan, C Jakob, GM McFarquhar, KN Bower, and GG Mace. 2008. "The Tropical Warm Pool International Cloud Experiment." Bulletin of the American Meteorological Society DOI: 10.1175/BAMS-89-5-629: 629-645.

McFarlane, SA, JH Mather, and TP Ackerman. 2007. "Analysis of tropical radiative heating profiles: A comparison of models and observations." Journal of Geophysical Research 112.

McFarquhar, GM, S Iacobellis, and RCJ Somerville. 2003. "SCM simulations of tropical ice clouds using observationally based parameterizations of microphysics." Journal of Climate 16(11): 1643-1664.

McFarquhar, GM, and SG Cober. 2004. "Sing-Scattering Properties of Mixed-Phase Arctic Clouds at Solar Wavelengths: Impacts on Radiative Transfer." Journal of Climate 17: 3799-3813.

Morcrette, JJ, EJ Mlawer, MJ Iacono, and SA Clough. 2001. "Impact of the Radiation Transfer Scheme RRTM in the ECMWF Forecasting System." ECMWF Newsletter 91: 2-9.

Morcrette JJ, H Barker, J Cole, M Iacono, and R Pincus. 2008. "Impact of a new radiation package, McRad, in the ECMWF Integrated Forecasting System." Monthly Weather Review (in press).

Naud, C, A Del Genio, GG Mace, S Benson, EE Clothiaux, and P Kollias. 2008. "Impact of dynamics and atmospheric state on cloud vertical overlap." Journal of Climate 21(8):1758-1770.

Ovtchinnikov, M, and SJ Ghan. 2005. "Parallel simulations of aerosol influence on clouds using cloud-resolving model and single-column models. Journal of Geophysical Research D: Atmospheres 110(D15) Art. No. D15S10.

Ovtchinnikov, M, T Ackerman, R Marchand, and M Khairoutdinov. 2006. "Evaluation of the multiscale modeling framework using data from the Atmospheric Radiation Measurement Program." Journal of Climate 19(9):1716-1729.

Penner, J, X Dong, and Y Chen. 2004. "Observational evidence of a change in radiative forcing due to the indirect aerosol effect." Nature 427(6971):231-234.

Pincus, R, HW Barker, and JJ Morcrette. 2003. "A fast, flexible, approximate technique for computing radiative transfer in inhomogeneous cloud fields." Journal of Geophysical Research D: Atmospheres 108(D13): Art. No. 4376.

Räisänen, P, HW Barker, and JNS Cole. 2005. “The Monte Carlo independent column approximation's conditional random noise: Impact on simulated climate." Journal of Climate 18(22):4715-4730.

Räisänen, P, S Järvenoja, H Järvinen, M Giorgetta, E Roeckner, K Jylhä, and K Ruosteenoja. 2007. "Tests of Monte Carlo independent column approximation in the ECHAM5 atmospheric GCM.” Journal of Climate 20(19):4995-5011. 
Randall, D, M Khairoutdinov, A Arakawa, and W Grabowski. 2003. "Breaking the cloud parameterization deadlock." Bulletin of the American Meteorological Society 84(11):1547-1564.

Revercomb, HE, DD Turner, DC Tobin, RO Knuteson, WF Feltz, J Barnard, J Bösenberg, S Clough, D Cook, R Ferrare, J Goldsmith, S Gutman, R Halthore, B Lesht, J Liljegren, H Linné, J Michalsky, V Morris, W Porch, S Richardson, B Schmid, M Splitt, T Van Hove, E Westwater, and D Whiteman. 2003. "The ARM Program's water vapor intensive observation periods: Overview, initial accomplishments, and future challenges." Bulletin of the American Meteorological Society 84(2):217-236.

Robock, A, L Luo, EF Wood, F Wen, KE Mitchell, PR Houser, JC Schaake, D Lohmann, B Cosgrove, J Sheffield, Q Duan, RW Higgins, RT Pinker, JD Tarpley, JD Basara, and KC Crawford. 2003. "Evaluation of the North American Land Data Assimilation System over the Southern Great Plains during the warm season." Journal of Geophysical Research D: Atmospheres 108(D22): Art. No. 8846.

Slingo, A, TP Ackerman, RP Allan, EI Kassianov, SA McFarlane, GJ Robinson, JC Barnard, MA Miller, JE Harries, JE Russell, and S Dewitte. 2006. "Observations of the impact of a major Saharan dust storm on the atmospheric radiation balance." Geophysical Research Letters 33(24): Art. No. L24817, doi:10.1029/2006GL027869.

Soden, BJ, DD Turner, BM Lesht, and LM Miloshevich. 2004. "An analysis of satellite, radiosonde, and lidar observations of upper tropospheric water vapor from the Atmospheric Radiation Measurement Program." Journal of Geophysical Research D: Atmospheres 109(D4): Art. No. D04105.

Solomon, S, D Qin, M Manning, Z Chen, M Marquis, KB Averyt, M Tignor and HL Miller (eds.). IPCC, 2007: Climate Change 2007: The Physical Science Basis. Contribution of Working Group I to the Fourth Assessment Report of the Intergovernmental Panel on Climate Change. Cambridge University Press, Cambridge, United Kingdom and New York, NY, USA, 996 pp.

Turner, DD, DC Tobin, SA Clough, PD Brown, RG Ellingson, EJ Mlawer, RO Knuteson, HE Revercomb, TR Shippert, WL Smith, and MW Shephard. 2004. "The QME AERI LBLRTM: A Closure Experiment for Downwelling High Spectral Resolution Infrared Radiance." Journal of the Atmospheric Sciences 61(22):2657-2675.

Turner, DD, BM Lesht, SA Clough, JC Liljegren, HE Revercomb, and DC Tobin. 2003. "Dry bias and variability in Vaisala RS80-H radiosondes: The ARM experience." Journal of Atmospheric and Oceanic Technologies 20(1):117-132.

Valero, FPJ, SK Pope, BC Bush, Q Nguyen, D Marsden, RD Cess, AS Simpson-Leitner, A Bucholtz, and PM Udelhofen. 2003. "Absorption of solar radiation by the clear and cloudy atmosphere during the Atmospheric Radiation Measurement Enhanced Shortwave Experiments (ARESE) I and II: Observations and models." Journal of Geophysical Research 108: doi:10.1029/2001JD001384 
Verlinde, J, JY Harrington, GM McFarquhar, VT Yannuzzi, A Avramov, S Greenberg, N Johnson, G Zhang, MR Poellot, JH Mather, DD Turner, EW Eloranta, BD Zak, AJ Prenni, JS Danier, GL Kok, DC Tobin, R Holz, K Sassen, D Spangenberg, P Minnis, TP Tooman, MD Ivey, SJ Richardson, CP Bahrmann, M Shupe, PJ DeMott, AJ Heymsfield, and R Schofield. 2007. "The Mixed-Phase Arctic Cloud Experiment (M-PACE), Bulletin of the American Meteorological Society 88(2):205-221.

Wu, J, A Del Genio, and AB Wolf. 2007. "Convection regimes during TWP-ICE and in the GISS SCM.” Poster Presentation at the Seventeenth Atmospheric Radiation Measurement (ARM) Science Team Meeting, ARM-CONF-2007, March, Monterey, California.

Wulfmeyer, V, A Behrendt, H-S Bauer, C Kottmeier, U Corsmeier, A Blyth, G Craig, U Schumann, M Hagen, S Crewell, P Di Girolamo, C Flamant, M Miller, A Montani, S Mobbs, E Richard, MW Rotach, M Arpagaus, H Russchenberg, P Schlussel, M Konig, V Gartner, R Steinacker, M Dorninger, DD Turner, T Weckwerth, A Hense, and C Simmer. 2008. "The convective and orographically-induced precipitation study: A research and development project of the World Weather Research Program for improving quantitative precipitation forecasting in low-mountain regions." Accepted for publication in Bulletin of the American Meteorological Society September 30, 2007.

Xie, S, M Zhang, JS Boyle, RT Cederwall, GL Potter, and W Lin. 2004: Impact of a revised convective triggering mechanism on Community Atmosphere Model Version 2 simulations: Results from short-range weather forecasts." Journal of Geophysical Research 109(D14): Art. No. D14102, doi:10.1029/2004JD004692.

Xie, S, and M Zhang. 2000. "Impact of the convection triggering function on single column model simulations." Journal of Geophysical Research D: Atmospheres 105(D11):14983-14996, doi:10.1029/2000JD900170.

Zhang, GJ. 2002. "Convective quasi-equilibrium in midlatitude continental environment and its effect on convective parameterization." Journal of Geophysical Research D: Atmospheres 107(D14): Art. No. 4220, doi:10.1029/2001JD001005. 